\title{
The role of neoadjuvant chemotherapy in the management of locally advanced cervix cancer: a systematic review
}

\author{
Mohammed Osman \\ Oncology Consultant, General Organization of Teaching Hospitals and Institutes, Cairo, Egypt
}

\begin{abstract}
Cervical cancer is the second most common cancer in women. Neoadjuvant chemotherapy for patients with locally advanced cervix cancer has comparable benefits to concurrent chemoradiotherapy (CCRT), but with fewer side effects. This systematic review aims to provide a comprehensive summary of the benefits of neoadjuvant chemotherapy for the management of locally advanced cervix cancer from stage IB2 (tumor $>4.0 \mathrm{~cm}$ ) to IIIB (tumor extending to the pelvic wall and/or hydronephrosis). Our primary objective was to assess benefits in terms of survival. The data source included the USA national library of medicine, Medline search, and the National Cancer Institute PDQ Clinical Protocols. Inclusion criteria for consideration in the current systematic review included studies published between January 1997 and December 2012. In terms of histology, they had to be focused on squamous cell carcinoma, adenosquamous carcinoma, and/or adenocarcinoma. Patients should be either chemotherapy naïve or cervix cancer chemotherapy naïve, and have a performance status $\leq 2$. The search in the above-mentioned scientific websites led to identify 49 publications, 19 of which were excluded, as they did not meet the inclusion criteria of this systematic review. Therefore only 30 studies
\end{abstract}

Correspondence: Mohammed Osman, 39 B Mostafa Basha Street, Elzaitoon, Cairo, Egypt. Tel.: +20222585380 .

E-mail: mmoneam@hotmail.com

Key words: neoadjuvant cervix chemotherapy, systemic quality survival.

Acknowledgments: the author would like to thank Dr. Selim H, MD, PhD, Temple University, USA, for his great contribution in the preparation of the statistics for this systematic review.

Conflict of interests: the author declares no potential conflict of interests.

Conference presentation: part of the paper was presented at the ESMO (European Society of Medical Oncology) Congress, Madrid 2014 - Poster presentation number: 920P.

Received for publication: 15 April 2014.

Revision received: 5 July 2014.

Accepted for publication: 8 July 2014.

This work is licensed under a Creative Commons Attribution NonCommercial 3.0 License (CC BY-NC 3.0).

(C) Copyright M. Osman, 2014

Licensee PAGEPress, Italy

Oncology Reviews 2014; 8:250

doi:10.4081/oncol.2014.250 were deemed eligible. Data was collected from 1760 patients enrolled in the current systematic review study. The mean age was 45.2 years. The mean tumor size was $4.7 \mathrm{~cm}$. The most commonly used chemotherapies were cisplatin doublets. Paclitaxel was the most commonly used chemotherapeutic agent in the doublets. The mean chemotherapy cycles were 2.7. After chemotherapy, patients underwent surgery after a mean time of 2.5 weeks. The standard operation was radical hysterectomy with pelvic lymphadenectomy. Chemotherapy achieved an objective response rate of $84 \%$. The 5 -year progression-free survival and overall survival were $61.9 \%$ and $72.8 \%$ respectively. The treatment protocol was associated with a mild early toxicity profile. Leucopenia and neutropenia were the most common side effects. Late toxicity was also generally mild and mainly associated with bladder dysfunction and vaginal dehiscence. The quality of the studies was assessed using the Newcastle-Ottawa quality assessment scale. Neoadjuvant chemotherapy achieved comparable survival results to CCRT, and was associated with less toxicity.

\section{Introduction}

cancer is the second most common cancer in women and affects 530,000 new patients annually ( $9 \%$ of new cases of cancer diagnosed in women). ${ }^{1}$ According to the staging system developed by the Féderation Internationale de Gynécologie et d'Obstétrique (FIG0), a locally advanced cervix cancer can range from stage IB2 (bulky tumor $>4.0 \mathrm{~cm}$ ) to stage IIIB (spread of the tumor in the pelvic wall and/or hydronephrosis). ${ }^{2}$ Concurrent chemoradiotherapy (CCRT) is considered the standard treatment for locally advanced cervix cancer. A systematic review and meta-analysis of data showed survival benefits, better local and distant control of CCRT when compared with radiotherapy alone..$^{3-5}$ However, CCRT is associated with considerable early toxicity in particular with gastrointestinal and hematological side effects. Many studies also showed significant long-term side effect rates. The study of Tan and Zahra and Green et al. showed grade 3 and 4 late toxicity with a range of $18.3 \%$ to $22 \%$, and reported urinary and/or intestinal complications. 5,6

\section{Rationale for the neoadjuvant chemotherapy}

Several studies showed that the neoadjuvant chemotherapy is effective in reducing the tumor size, expediting the elimination of micrometastasis, improving operability and surgical downstaging. Furthermore, the combination of chemotherapy followed by surgery is associated with fewer side effects than concurrent chemotherapy and radiotherapy. ${ }^{7,8}$ 


\section{Study objectives}

This systematic review aimed to provide a comprehensive summary of the benefits of neoadjuvant chemotherapy in the management of locally advanced cervix cancer. The primary endpoint was the survival benefit, including overall survival (OS) and progression-free survival (PFS). The secondary end points were treatment response, and toxicity profiles.

\section{Materials and Methods}

\section{Study design, search method}

The data source included the USA national library of medicine (http:/www.ncbi.nlm.nih.gov/pubmed), Medline search (http://clinicaltrials.gov/ct2/search/advanced), and the National Cancer Institute PDQ Clinical Protocols (http://www.cancer.gov/clinicaltrials/search). The literature search was conducted in English.

\section{Inclusion and exclusion criteria}

Inclusion criteria for trial consideration included studies published between $1^{\text {st }}$ January 1997 and $31^{\text {st }}$ December 2012 and studies with FIG0 stages IB2 to IIIB. Histologies included squamous cell carcinoma, adenosquamous carcinoma, and/or, adenocarcinoma. Studies had to be prospective only, and either phase II, or III. Patients should be either chemotherapy naïve or cervix cancer chemotherapy naïve. The patient performance status had to be an Eastern Cooperative Oncology Group (ECOG) score less than or equal to 2.0. Exclusion criteria included patients with metastatic cervix cancer including FIG0 stages IVA, and, or IVB, phase 1 trials, retrospective studies and case presentations. Trials including radiotherapy as part of the neoadjuvant treatment and studies of small-cell cancer cancers, clear-cell cancers, or other rare pathological variants were also excluded.

\section{Outcome measures}

OS was defined as the time from the beginning of treatment until death or the last follow up date of the study. PFS was defined as the time from the beginning of treatment until progression, relapse, recurrence, death, or the last follow up date. Treatment response was either complete remission (CR), partial remission (PR), stable disease (SD), or disease progression (DP). CR, PR, and SD were pooled together to generate the objective response rate (ORR).

\section{Data collection and analysis}

The study gathered information from eligible studies, such as patient and disease characteristics, chemotherapy used in neoadjuvant setting, operative details, response to treatment, survival and treatment-related side effects.

\section{Assessment of the quality of the included studies}

In the systematic review the quality of the included studies was assessed using the Newcastle-Ottawa quality assessment scale, which is based on three items: patient selection, comparability of groups and ascertainment of outcome. Studies were evaluated on the basis of a star scoring scale with higher scores for high quality studies. ${ }^{9}$

\section{Statistical analysis}

The statistical analysis was performed using Stat Mate version III. Data was pooled from the included trials and analyzed on the basis of means, medians, and 95\% confidence intervals. Studies that did not include these items were mentioned in order to avoid selection biases. Response and survival data were analyzed by pooled analysis, and chisquare test. Pooled survival data was calculated with the Kaplan-Meier method. Survival curves were analyzed using the Log-rank (MantelCox) test. For phase III trials, a comparison was made between the survival rates of neoadjuvant chemotherapy and other treatments, generating a forest plot. The statistical heterogeneity was analyzed by either $\mathrm{X}^{2}$, or $\mathrm{I}^{2}$ test. A P value higher than 0.10 for the $\mathrm{X}^{2}$ test and/or a $\mathrm{I}^{2}$ value lower than $25 \%$ were interpreted as having a low level of heterogeneity. The publication bias was assessed by visual inspection of funnel plots.

\section{Results}

Searching studies published between $01^{\text {st }}$ January 1997 and $31^{\text {st }}$ December 2012 in the above-mentioned scientific websites by typing some or all words of the phrase neoadjuvant chemotherapy then surgery in locally advanced cervix cancer enabled us to identify 49 publications. Out of the total, 19 trials were excluded, because they did not meet the inclusion criteria. Of the excluded trials, 7 had radiotherapy as part of the preoperative or postoperative treatment, 3 had patients with smallcell carcinoma, 1 was a case study, 2 were retrospective studies and 6 more studied were excluded as they included stage IVA and/or IB1 cases. Thirty studies were deemed eligible to be included in this systematic review. Data was collected from 1760 patients enrolled in the above-mentioned studies (22 studies were phase II trials and 8 were phase III trials).

\section{Patients' characteristics}

Table 1 reports patient and disease characteristics.

\section{Treatment protocol}

\section{Neoadjuvant chemotherapy}

All studies, ${ }^{1-44}$ except the study by Lacava et al. ${ }^{40}$ used chemotherapy doublets, or triplets. The most commonly used chemotherapy agents were platinum derivatives and were used in 28 out of 30 studies. Platinum derivatives were either cisplatin, carboplatin, or nedaplatin.

Table 1. Patients' characteristics.

\begin{tabular}{|c|c|c|}
\hline & No. (total: 1760) & $\%$ \\
\hline \multicolumn{3}{|l|}{ Age } \\
\hline Mean & 45.2 years old & - \\
\hline Median & 45 years old & - \\
\hline $95 \% \mathrm{CI}$ & 39.3-51.5 years old & - \\
\hline \multicolumn{3}{|l|}{ Tumor size } \\
\hline Mean & $4.7 \mathrm{~cm}$ & - \\
\hline Median & $4.4 \mathrm{~cm}$ & - \\
\hline $95 \% \mathrm{CI}$ & $3.5-5.2$ & - \\
\hline \multicolumn{3}{|l|}{ FIGO stage } \\
\hline Ib2-IIA & 1230 & 69.8 \\
\hline IIb-IIIA & 335 & 19.2 \\
\hline IIIB & 195 & 11.0 \\
\hline \multicolumn{3}{|l|}{ Pathological type } \\
\hline Squamous-cell carcinoma & 1680 & 95.4 \\
\hline Adenocarcinoma & 55 & 3.1 \\
\hline Adenosquamous & 25 & 1.5 \\
\hline \multicolumn{3}{|l|}{ Performance status } \\
\hline 0 & 1448 & 82.2 \\
\hline $1-2$ & 244 & 13.8 \\
\hline Unknown & 68 & 3.8 \\
\hline
\end{tabular}


They were included in $25,2,1$ studies, respectively. The mean chemotherapy cycles were 2.7 cycles, and the median was 3 cycles [ $95 \%$ confidence interval (CI): 2-4]. Table $2^{10-16,18-40}$ indicates chemotherapy agents used in the 30 trials. Following chemotherapy, radiological assessment was conducted by abdominal-pelvic computed tomography in $93.3 \%$, and magnetic resonance imaging in the remaining $6.7 \%$ of the included trials.

\section{Chemotherapy results}

All the 1760 patients were evaluated for response: 247 patients reported a CR, 880 patients reported a $\mathrm{PR}$, and 352 patients reported a SD. The remaining 281 patients had a DP. The ORR of the systematic review was $84 \%$. Trials that included platinum derivatives had an ORR of $79 \%$. Their pooled CR and PR were $66 \%$. While studies that did not include platinum derivatives had an ORR of $80 \%$, with pooled CR and PR of $67 \%$. Considering the studies of platinum derivatives, trials based on cisplatin had an ORR of 76\%, with pooled CR and PR of $63 \%$, whereas studies that did not include cisplatin achieved an ORR of 78\%, with pooled CR and PR of $65 \%$. The $P$ value was 0.07 . The response evaluation by stage was carried out in 22 out of the 30 trials. The remaining 8 studies did not define the response by stage (Figure 1).

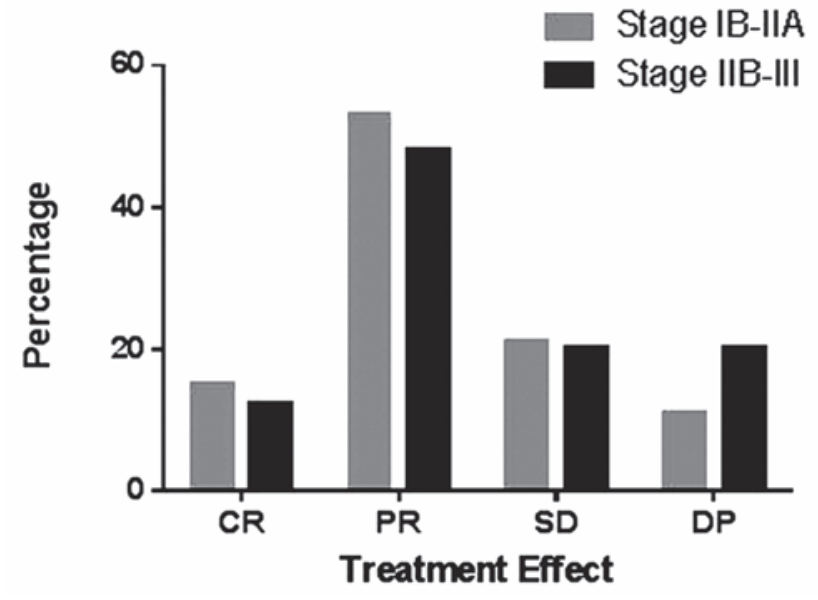

Figure 1. Treatment response by stage. CR, complete remission; PR, partial remission; SD, stable disease; DP, disease progression.

Table 2. Chemotherapy agents used in the 30 trials.

\begin{tabular}{|c|c|c|}
\hline Study & Chemotherapy regimen, doses & No. of cycles \\
\hline Shoji et al., $2013^{10}$ & Carboplatin (AUC6), paclitaxel $\left(175 \mathrm{mg} / \mathrm{m}^{2}\right) /$ docetaxel $\left(70 \mathrm{mg} / \mathrm{m}^{2}\right)$ & $\begin{array}{l}2 \text { (18 patients) } \\
3 \text { (5 patients) }\end{array}$ \\
\hline Shen et al., $2012^{11}$ & Cisplatin (20 mg/m² D1-4)/carboplatin (AUC5), paclitaxel $\left(150 \mathrm{mg} / \mathrm{m}^{2}\right)$ & 2 \\
\hline Yamaguchi et al., $2012^{12}$ & Nedaplatin $\left(80 \mathrm{mg} / \mathrm{m}^{2}\right)$, irinotecan $\left(60 \mathrm{mg} / \mathrm{m}^{2} \mathrm{D} 1,8\right)$ & 3 \\
\hline Pinheiro et al., $2011^{13}$ & Mitomycin C (10 mg/m²), methotrexate (300 mg/m² with folonic acid), bleomycin $\left(15 \mathrm{mg} / \mathrm{m}^{2} \mathrm{D} 1,8\right)$ & 4 \\
\hline Vizza et al., $2011^{14}$ & Cisplatin $\left(75 \mathrm{mg} / \mathrm{m}^{2}\right)$, paclitaxel $\left(175 \mathrm{mg} / \mathrm{m}^{2}\right)$, ifosfamide $\left(5 \mathrm{~g} / \mathrm{m}^{2}\right.$, mesna $)$ & 3 \\
\hline Mossa et al., $2010^{15}$ & Cisplatin $\left(50 \mathrm{mg} / \mathrm{m}^{2}\right)$, vincristine $\left(1 \mathrm{mg} / \mathrm{m}^{2}\right)$, bleomycin $\left(25 \mathrm{mg} / \mathrm{m}^{2} \mathrm{D} 1,8\right)$ & 3 \\
\hline Shoji et al., $2010^{16}$ & Cisplatin $\left(70 \mathrm{mg} / \mathrm{m}^{2}\right)$, irinotecan $\left(70 \mathrm{mg} / \mathrm{m}^{2} \mathrm{D} 1,8\right)$ & 2 \\
\hline Cho et al., $2009^{18}$ & Cisplatin $\left(75 \mathrm{mg} / \mathrm{m}^{2}\right) /$ carboplatin (AUC5), paclitaxel $\left(135 \mathrm{mg} / \mathrm{m}^{2}\right)$ & 2 \\
\hline Kokawa et al., $2007^{19}$ & $\begin{array}{l}\text { Mitomycin-C }\left(10 \mathrm{mg} / \mathrm{m}^{2}\right) \text {, irinotecan }\left(100 \mathrm{mg} / \mathrm{m}^{2}\right) \mathrm{D} 1,8,15 \\
\text { Out of } 28 \text { days cycles }\end{array}$ & $\begin{array}{l}2 \text { (28 patients) } \\
3 \text { (7 patients) }\end{array}$ \\
\hline Sláma et al., $2007^{20}$ & Cisplatin $\left(50 \mathrm{mg} / \mathrm{m}^{2}\right)$, ifosfamide $\left(5 \mathrm{~g} / \mathrm{m}^{2}\right.$, mesna) & 3 \\
\hline Eddy et al., 200721 & Cisplatin, vincristine & 3 \\
\hline Choi et al., $2006^{22}$ & Cisplatin $\left(100 \mathrm{mg} / \mathrm{m}^{2}\right), 5$-fluorouracil $\left(1000 \mathrm{mg} / \mathrm{m}^{2} /\right.$ day D2-5) & 2 \\
\hline Cai et al., $2006^{23}$ & Cisplatin $\left(100 \mathrm{mg} / \mathrm{m}^{2}\right), 5$-fluorouracil $\left(1000 \mathrm{mg} / \mathrm{m}^{2} /\right.$ day D2-5) & 2 \\
\hline Termrungruanglert et al., $2005^{24}$ & Cisplatin $\left(70 \mathrm{mg} / \mathrm{m}^{2}\right)$, gemcitabine $\left(1000 \mathrm{mg} / \mathrm{m}^{2} \mathrm{D} 1,8\right)$ & 2 \\
\hline Taneja et al., $2005^{25}$ & Cisplatin $\left(50 \mathrm{mg} / \mathrm{m}^{2}\right)$, bleomycin $\left(15 \mathrm{mg} / \mathrm{m}^{2} \mathrm{D} 1,2\right)$, vincristine $\left(1 \mathrm{mg} / \mathrm{m}^{2}\right)$ & 3 \\
\hline DeSouza et al., $2004^{26}$ & Cisplatin $\left(60 \mathrm{mg} / \mathrm{m}^{2}\right)$, methotrexate $\left(300 \mathrm{mg} / \mathrm{m}^{2}\right.$ with folonic acid), bleomycin $\left(30 \mathrm{mg} / \mathrm{m}^{2}\right.$ twice weekly) & 3 \\
\hline Huang et al., $2003^{27}$ & Cisplatin $\left(50 \mathrm{mg} / \mathrm{m}^{2}\right)$, bleomycin $\left(15 \mathrm{mg} / \mathrm{m}^{2} \mathrm{D} 1,2\right)$, vincristine $\left(1 \mathrm{mg} / \mathrm{m}^{2}\right)$ & 3 \\
\hline Napolitano et al., $2003^{28}$ & Cisplatin $\left(50 \mathrm{mg} / \mathrm{m}^{2}\right)$, bleomycin $\left(15 \mathrm{mg} / \mathrm{m}^{2} \mathrm{D} 1,2\right)$, vincristine $\left(1 \mathrm{mg} / \mathrm{m}^{2}\right)$ & 3 \\
\hline D'Agostino et al., $2002^{29}$ & Cisplatin $\left(100 \mathrm{mg} / \mathrm{m}^{2}\right)$, epirubicin $\left(100 \mathrm{mg} / \mathrm{m}^{2}\right)$, paclitaxel $\left(175 \mathrm{mg} / \mathrm{m}^{2}\right)$ & 3 \\
\hline Benedetti-Panici et al., $2002^{30}$ & Cisplatin $\left(80 \mathrm{mg} / \mathrm{m}^{2}\right)$, vincristine $\left(1 \mathrm{mg} / \mathrm{m}^{2}\right)$, bleomycin ( $25 \mathrm{mg} / \mathrm{m}^{2} 3$ days $)$ & 2 \\
\hline Duenas-Gonzalez et al., $2003^{31}$ & Carboplatin (AUC 6), paclitaxel $\left(175 \mathrm{mg} / \mathrm{m}^{2}\right)$ & 3 \\
\hline Duenas-Gonzalez et al., $2002^{32}$ & Cisplatin $\left(100 \mathrm{mg} / \mathrm{m}^{2}\right)$, gemcitabine $\left(1 \mathrm{mg} / \mathrm{m}^{2} \mathrm{D} 1,8\right)$ & 3 \\
\hline Costa et al., $2001^{33}$ & Cisplatin $\left(40 \mathrm{mg} / \mathrm{m}^{2}\right)$, epirubicin $\left(30 \mathrm{mg} / \mathrm{m}^{2}\right)$, etoposide $\left(75 \mathrm{mg} / \mathrm{m}^{2}\right)$, bleomycin $(15 \mathrm{mg} \mathrm{D} 1,2)$ & 3 \\
\hline MacLeod et al., $2001^{34}$ & Cisplatin $\left(50 \mathrm{mg} / \mathrm{m}^{2}\right) /$ carboplatin (AUC5) based combination & 3 \\
\hline Aoki et al., $2001^{35}$ & Cisplatin $\left(60 \mathrm{mg} / \mathrm{m}^{2}\right)$, vinblastine $\left(4 \mathrm{mg} / \mathrm{m}^{2} \mathrm{D} 1,2\right)$, bleomycin $\left(25 \mathrm{mg} / \mathrm{m}^{2} 3\right.$ days $)$ & 2 \\
\hline Hwang et al., $2001^{36}$ & Cisplatin $\left(50 \mathrm{mg} / \mathrm{m}^{2}\right)$, vinblastine $\left(6 \mathrm{mg} / \mathrm{m}^{2}\right)$, bleomycin ( $25 \mathrm{mg} / \mathrm{m}^{2} 3$ days $)$ & 3 \\
\hline Chang et al., $2000^{37}$ & Cisplatin $\left(50 \mathrm{mg} / \mathrm{m}^{2}\right)$, vincristine $\left(1 \mathrm{mg} / \mathrm{m}^{2}\right)$, bleomycin ( $25 \mathrm{mg} / \mathrm{m}^{2}$ for 3 days $)$ & 3 \\
\hline Zanetta et al., $1998^{38}$ & Cisplatin $\left(50 \mathrm{mg} / \mathrm{m}^{2}\right)\left(75 \mathrm{mg} / \mathrm{m}^{2}\right.$ in 10 patients), paclitaxel $\left(175 \mathrm{mg} / \mathrm{m}^{2}\right)$, ifosfamide $\left(5 \mathrm{~g} / \mathrm{m}^{2}\right.$, mesna) & 3 \\
\hline Sardi et al., $1997^{39}$ & Cisplatin $\left(50 \mathrm{mg} / \mathrm{m}^{2}\right)$, vincristine $\left(1 \mathrm{mg} / \mathrm{m}^{2}\right)$, bleomycin $\left(25 \mathrm{mg} / \mathrm{m}^{2} \mathrm{D} 1-3\right)$ & 3 \\
\hline Lacava et al., $1997^{40}$ & Vinrolbine (30 mg/m² weekly) & 4 \\
\hline
\end{tabular}




\section{Surgery}

Among the 1760 patients who received the neoadjuvant chemotherapy, 1596 (90\%) of them underwent surgery, which was performed after a mean time of 2.5 weeks (95\% CI: 2-5 weeks) after the end of chemotherapy. The standard operation was radical hysterectomy with pelvic lymphadenectomy (type III, or IV). A total of 100 patients (5.6\%) underwent also para-aortic lymphadenectomy due to positive para-aortic lymphnodes.

\section{Survival results}

Only 26 out of the 30 studies measured survival. The survival rates were not reported in 4 studies. ${ }^{11,16,20,40}$ These 4 trials evaluated the treatment response as an objective treatment effect and did not include survival data. Additionally, 5 more trials ${ }^{18,26,31,35,39}$ were excluded from the survival analysis, because they included postoperative radiotherapy in the treatment protocol. In the remaining 21 studies, survival was assessed at 24 months, and/or 60 months. PFS and OS were measured at 24 months in 5 studies, at 60 months in 12 studies and at both 24 and 60 months in 4 studies ( 2 of which also measured survival at 10 years).

Table $3^{10,12-15,19,21-25,27-30,32-34,36-38}$ reports the detailed survival rates of the 21 trials.

In the systematic review, the mean 2-year PFS was $75 \%$, and the median 2-year PFS was 76\%. The mean 5-year PFS was 61.9\%, and the median 5-year PFS was $67.5 \%$. The mean 2 -year OS was $82.1 \%$, and the median 2 -year OS was $82 \%$. The mean 5 -year OS was $72.8 \%$, and the median 5-year OS was 70.7\%. Two studies measured the 10 -year OS and PFS. The mean 10-year PFS was 61\%, and the mean 10-year OS was $68 \%$. In 14 out of the 21 studies survival was identified on the basis of the different stages of the locally advanced cervix cancer. For stage IB2IIA, the mean 2-year PFS was $79.1 \%$ and the 2 -year OS was $86 \%$. The mean 5-year PFS was $72 \%$, and the mean 5 -year OS was $83.4 \%$. For stage IIB-III, the mean 2-year PFS was $69 \%$ and the mean 2-year OS was $75 \%$. The mean 5 -year PFS was $58.9 \%$, and the mean 5 -year OS was $62 \%$ (Table 4; Figure 2). For PFS data, the Chi square $\left(\chi^{2}\right)$ was 4.794 , the
A

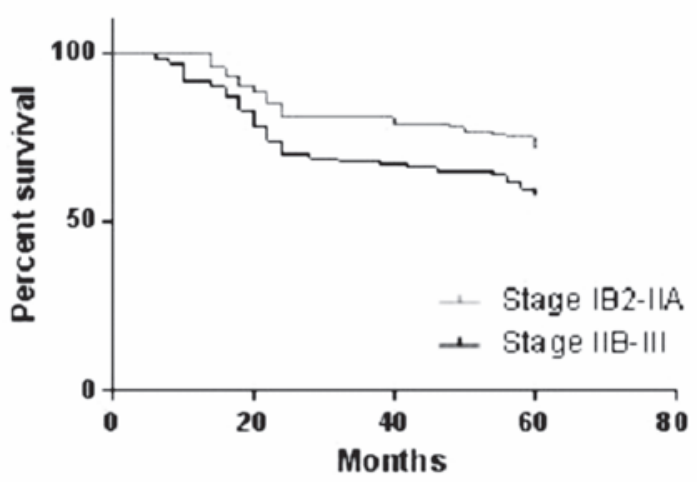

B

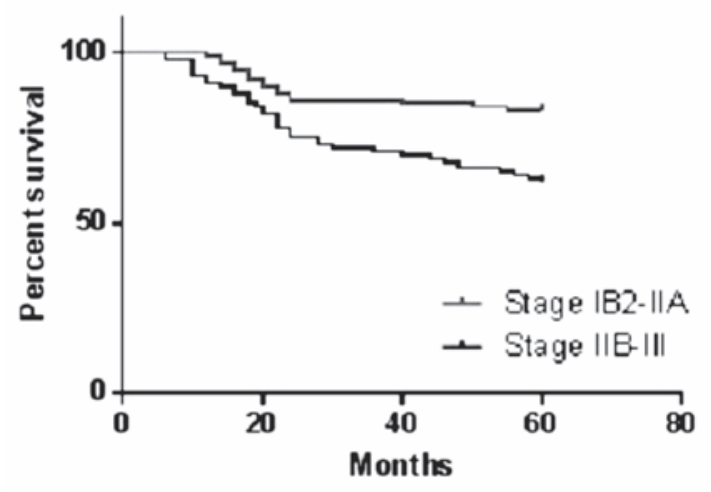

Figure 2. Survival result of the systematic review. A) Progression free survival (PFS) of the study group; B) overall survival (OS) of the study group.

Table 3. Details of the survival results of the 21 trials.

\begin{tabular}{|c|c|c|c|c|c|c|c|}
\hline Study & Patients no. & Trial phase & Stage & 2 year PFS\% & 2 year OS\% & 5 year PFS\% & 5 year 0s\% \\
\hline Shoji et al., $2013^{10}$ & 18 & II & Ib2-IIb & 64 & 78 & 60 & 68 \\
\hline Yamaguchi et al., 2012 12 & 66 & II & Ib2-IIb & 73.8 & 76 & - & - \\
\hline Pinheiro et al., $2011^{13}$ & 27 & II & Ib2-IIIb & - & - & 59 & 67 \\
\hline Vizza et al., $2011^{14}$ & 40 & II & Ib2-Ilb & 87.5 & 90 & - & - \\
\hline Mossa et al., $2010^{15}$ & 153 & II & Ib2-IIIb & - & - & 65.4 & 70.4 \\
\hline Kokawa et al., $2007^{19}$ & 33 & II & Ib2-IIIb & 77 & 84 & 69 & 72 \\
\hline Eddy et al., $2007^{21}$ & 145 & II & $\mathrm{Ib} 2$ & - & - & 71 & 78 \\
\hline Choi et al., $2006^{22}$ & 62 & III & Ib2-Ila & 77 & 82 & 71 & 76.4 \\
\hline Cai et al., $2006^{23}$ & 52 & III & Ib2 & - & - & 72.7 & 84.6 \\
\hline Termrungruanglert et al., $2005^{24}$ & 25 & II & $\mathrm{Ib} 2$ & 81 & 88.9 & - & - \\
\hline Taneja et al., $2005^{25}$ & 22 & II & Ib2-IIIb & - & - & 62 & 69 \\
\hline Huang et al., $2003^{27}$ & 102 & II & Ib2-Ila & - & - & 65 & 69 \\
\hline Napolitano et al., $2003^{28}$ & 106 & III & Ib2-IIb & - & - & 71.7 & 76.4 \\
\hline D'Agostino et al., $2002^{29}$ & 42 & II & Ib2-Ila & - & - & 85 & 90 \\
\hline Benedetti-Panici et al., $2002^{30}$ & 152 & III & Ib2-IIlb & - & - & 56.5 & 61 \\
\hline Duenas-Gonzalez et al., $2002^{32}$ & 23 & II & Ib2-IIIb & 65 & 69 & - & - \\
\hline Costa et al., 200133 & 16 & II & Ib2-IIa & - & - & 67 & 71 \\
\hline MacLeod et al., $2001^{34}$ & 46 & II & IIIb & - & - & 54 & 60 \\
\hline Hwang et al., $2001^{36}$ & 80 & III & Ib2-IIIb & - & - & 78.7 & 82 \\
\hline Chang et al., $2000^{37}$ & 68 & III & Ib2-IIa & 74 & 81 & 68 & 70 \\
\hline Zanetta et al., $1998^{38}$ & 32 & II & Ib2-IIIb & 76 & 90 & - & - \\
\hline
\end{tabular}

PFS, progression free survival; OS, overall survival. 
degree of freedom was 1 , and the hazard rate $(\log$ rank) was 0.5879 , 1.684. $(\mathrm{P}=0.0286)$ For OS data, the Chi square $\left(\chi^{2}\right)$ was 8.81 , the degree of freedom was 1 , and the hazard rate (log rank) was 0.3989 , 2.507. ( $\mathrm{P}=0.001$ ) For the 6 phase III trials, a comparison was made between the group that received neoadjuvant chemotherapy and the control group that received surgery alone in 1 study, radiotherapy alone in 1 , and concurrent chemoradiation in 4 trials. Figure 3 reports the forest plot which was generated.

\section{Pattern of relapse}

All the 21 studies that assessed survival reported relapse data. In this study, the 2-year relapse rate was $25 \%$, and the 5 -year relapse rate was $32.5 \%$. During the $1^{\text {st }} 2$-years follow-up, the locoregional pattern occurred in $60 \%$ of relapsed patients, whereas a disseminated relapse occurred in $40 \%$ of them. For the 5 -year follow-up period, locoregional relapse occurred in $52 \%$ of the relapsed patients, whereas a disseminated relapse occurred in $28 \%$ of them. The remaining $20 \%$ were categorized as unidentified relapse.

\section{Toxicity profile}

Early toxicity was defined as toxicity that occurred during treatment until 6-8 weeks after chemotherapy. Late toxicity was defined as toxicity that occurred $>6-8$ weeks after the end of the treatment protocol.

\section{Early toxicity}

All 21 studies that assessed survival reported data about early toxicity. Grade 3 and 4 toxicity was classified as hematological, and nonhematological. Among all early toxic effects, leucopenia and neutropenia were the most common and occurred in $18.3 \%$ and $33.3 \%$ of chemotherapy cycles respectively.

Table 5 reports grade 3 and 4 toxicity profiles that occurred $\geq 1 \%$ of cycles and the corresponding percentage.

A delay of 1-2 weeks in the chemotherapy cycles was required in $15 \%$ of cycles. No deaths due to documented chemotherapy side effects.

A common complication associated with surgery was intraoperative bleeding, which occurred in $3.5 \%$ of patients.

\section{Late toxicity}

Only 8 studies included data about late toxicity. The most common side effect due to late toxicity was bladder dysfunction and occurred in $25 \%$ of patients. All were grade 1 or 2 . Vaginal dehiscence and dyspareunia were the second most common late side effect. They occurred in $7.5 \%$ of patients. They were also grade 1 or 2 . Other common late side effects included grade 1 or 2 peripheral neuropathy that occurred in 7\% of patients. Other less common late side effects included lower limb edema (1\%), and bowel obstruction (0.6\%). One severe late side effect was represented by fistulae that occurred in $2 \%$ of patients.

\section{Quality assessment}

In order to assess the quality of the 30 studies included, the questionnaire foreseen by the Newcastle-Ottawa quality assessment scale for cohort studies was used. Collectively, the studies included scored a mean of 2.2 for patient selection item, 1 for the comparability of the group item, and 1.6 for the ascertainment of the outcome item.

\section{Discussion}

Nearly $50 \%$ of patients presented a locally advanced cancer cervix. The standard treatment was CCRT. Many randomized trials evaluated the benefits of CCRT including that of Morris et al., ${ }^{43}$ in which 403 patients were randomized to receive either radiotherapy or CCRT with cisplatin and 5 fluorouracil. The 5 -year OR was $67 \%$ among patients in the CCRT group and $40 \%$ among patients in the radiotherapy group $(\mathrm{P}<0.001)$. Furthermore, the rates of both distant metastases and locoregional recurrences were significantly higher among patients treated with radiotherapy alone $(\mathrm{P}<0.001){ }^{43}$

When comparing the results of the systematic review with those of Morris et al. ${ }^{43}$ neoadjuvant chemotherapy seemed to be equivalent to CCRT in terms of survival benefit. As to early toxicity, the study of Morris et al. ${ }^{43}$ showed that early side effects occurred in $64 \%$ of the group that underwent CCRT, with hematological side effects being the most common (37\% of cycles). This study showed slightly lower early

Table 4. Mean survival results of the systematic review.

\begin{tabular}{lccc} 
& 2 & 5 & 10 \\
& years $(\%)$ & years $(\%)$ & years $(\%)$ \\
Progression free survival & & & \\
$\quad$ All stages & 75 & 61.9 & 61 \\
Stage IB2-IIA & 79.1 & 72 & Not identified \\
Stage IIB-III & 69 & 58.9 & Not identified \\
Overall survival & & & \\
All stages & 82.1 & 72.8 & 68 \\
Stage IB2-IIA & 86 & 83.4 & Not identified \\
Stage IIB-III & 75 & 62 & Not identified \\
\hline
\end{tabular}

Table 5. Grade 3 and 4 toxicity profiles that occurred $\geq 1 \%$ of cycles and their percentage.

\begin{tabular}{lc} 
Toxicity & $\%$ \\
Hematological side effects & \\
Leucopenia & 18.3 \\
Neutropenia & 33.3 \\
Febrile neutropenia & 3 \\
Anemia & 5.5 \\
Thrombocytopenia & 2.7 \\
Non-hematological side effects & \\
Nausea, vomiting & 10 \\
Liver toxicity & 1.3 \\
Diarrhea & 1.2 \\
Peripheral neuropathy & 1 \\
\hline
\end{tabular}

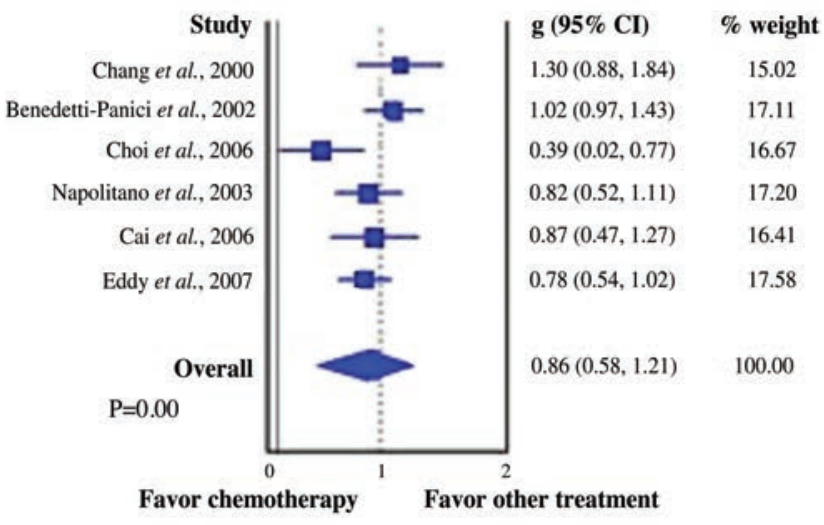

Figure 3. Comparison of the trials which favor neoadjuvant chemotherapy $v s$ other treatment. 
toxicity rates. On the contrary, a significant difference between this study and that of Morris et al. ${ }^{43}$ was identified in terms of late toxicity. The study of Morris et al. that assessed late toxicity over a period of 43 months reported grade 3 , and 4 late toxicity in $17.6 \%$ patients, with large bowel, and rectal side effects being the highest. Furthermore, many recent studies showed worse late sequelae associated with CCRT especially when considering long follow up periods. $5,6,43$

The primary objective of this study was to assess the benefits of neoadjuvant chemotherapy in terms of survival in locally advanced cancer cervix. Survival is the main target for this treatment having curative intent.

The studies on the role of neoadjuvant chemotherapy in the management of locally advanced cancer cervix were limited, because the standard treatment offered considerable efficacy. On the basis of the inclusion criteria, scientific websites were rigorously screened to identify eligible trials. All the included trials fulfilled all predetermined inclusion criteria items. The study of Shoji et al. ${ }^{10}$ was published online in 2012 , as clarified by the authors. The author preferred to exclude patients with stage IVA diseases. Although stage IVa is considered to be associated with a locally advanced disease, but including data from such extensive disease may flaw the results, and increase the heterogeneity of the trial.

The main challenge in this analysis was the heterogeneity of the included data, because the systematic review was based on a large number of trials, and most of them included a small number of patients (77\% of trials included less than 60 patients). The author opted to include data from a large number of trials published over long period of time to come to a conclusion based on a large number of data. In order to decrease heterogeneity, the researcher performed a comparison between the results in terms of survival of neoadjuvant chemotherapy and other treatments for the included phase III trials. The researcher performed such comparison in order to confirm the conclusion based on a less heterogeneous sample. Furthermore, the quality of the included trials was assessed using the Newcastle-Ottawa quality assessment scale. This scale provided good information about the quality of nonrandomized trials in the meta-analysis and was arguably used for this study that included a large number of trials with a small number of patients.

The quality of this systematic review was assessed on the basis of the PRISMA 2009 checklist criteria by an independent reviewer, and found to meet the criteria of systematic reviews. ${ }^{22}$ Furthermore, the statistical analysis performed in this study was considered advanced as defined by Garg et al. ${ }^{42}$

The neoadjuvant chemotherapy represents a reasonable treatment option for locally advanced cancer cervix. It achieved a mean ORR of $84 \%$, a 5 -year PFS of $61.9 \%$, and a 5 -year OS of $72.8 \%$. Chemotherapy had a mild toxicity profile. Furthermore the neoadjuvant chemotherapy had also a mild late toxicity profile.

Considering that many chemotherapy regimens are available with many combinations and with cisplatin as main agent, this systematic review failed to identify the combination offering the best result. However, all the regimens achieved comparable results. It would be reasonable to recommend further trials to solve this unclear point. One should also take into consideration the recent systematic review by Lorusso et al., which showed that cisplatin-based chemotherapy achieved better survival results compared with carpoplatin-based chemotherapy in cancer cervix. ${ }^{4}$

For the purpose of the analysis of survival, relapses and late toxicity, both studies that did not include survival data were excluded. This study excluded also studies with postoperative radiotherapy, as they may affect the results in terms of survival and toxicity, but were included only in the calculation of the response data to the neoadjuvant chemotherapy.

\section{Conclusions}

The neoadjuvant chemotherapy is a reasonable treatment option for locally advanced cancer cervix. It achieved comparable survival benefits to CCRT, and was associated with fewer side effects. More trials are needed to clarify many unclear points, including the best chemotherapeutic regimen, and late side effects preferably in comparison with CCRT.

\section{References}

1. Ferlay J, Shin HR, Bray F, et al. Cancer incidence and mortality worldwide: IARC Cancer Base No. 10. Lyon: International Agency for Research on Cancer; 2010.

2. Pecorelli S. Revised FIGO staging for carcinoma of the vulva, cervix, and endometrium. Int J Gynaecol Obstet 2009;105:103-4.

3. Monk BJ, Tewari KS, Koh WJ. Multimodality therapy for locally advanced cervical carcinoma: state of the art and future directions. J Clin Oncol 2007;25:2952-65.

4. Thomas GM. Improved treatment for cervical cancer-concurrent chemotherapy and radiotherapy. N Engl J Med 1999;340:1198-200.

5. Green JA, Kirwan JM, Tierney JF, et al. Survival and recurrence after concomitant cehmotherapy and radiotherapy for cancer of the uterine cervix: a systematic review and meta-analysis. Lancet 2001;358:781-6.

6. Tan LT, Zahra M. Long-term survival and late toxicity after chemoradiotherapy for cervical cancer - The Addenbrooke's experience. Clin Oncol (R Coll Radiol) 2008;20:358-64.

7. Huang HJ, Chang TC, Hong JH, et al. Prognostic value of age and histologic type in neoadjuvant chemotherapy plus radical surgery for bulky $(>/=4 \mathrm{~cm})$ stage IB and IIA cervical carcinoma. Int $\mathrm{J}$ Gynecol Cancer 2003;13:204-11.

8. Panici PB, Scambia G, Baiocchi G, et al. Neoadjuvant chemotherapy and radical surgery in locally advanced cervical cancer. Prognostic factors for response and survival. Cancer 1998;67:372-9.

9. Stang A. Critical evaluation of the Newcastle-Ottawa scale for the assessment of the quality of nonrandomized studies in meta-analyses. Eur J Epidemiol 2010;25:603-5.

10. Shoji T, Takatori E, Saito T, et al. Neoadjuvant chemotherapy using platinum- and taxane-based regimens for bulky stage Ib2 to IIb non-squamous cell carcinoma of the uterine cervix. Cancer Chemother Pharmacol 2013;71:657-62.

11. Shen Y, Yang L, Wang Z. Treatment of early bulky cervical cancer with neoadjuvant paclitaxel, carboplatin and cisplatin prior to laparoscopical radical hysterectomy and pelvic lymphadenectomy. Oncol Lett 2012;3:641-5.

12. Yamaguchi S, Nishimura R, Yaegashi N, et al. Phase II study of neoadjuvant chemotherapy with irinotecan hydrochloride and nedaplatin followed by radical hysterectomy for bulky stage Ib2 to Ilb, cervical squamous cell carcinoma: Japanese Gynecologic Oncology Group study (JGOG 1065). Oncol Rep 2012;28:487-93.

13. Pinheiro W, Pereira AK, Soares JM Jr, et al. Is the combination of mitomycin $\mathrm{C}$, bleomycin and methotrexate effective as aneoadjuvant treatment for cervical cancer in women. Eur J Gynaecol Oncol 2011;32:37-9.

14. Vizza E, Pellegrino A, Milani R, et al. Total laparoscopic radical hysterectomy and pelvic lymphadenectomy in locally advanced stage IB2-IIB cervical cancer patients after neoadjuvant chemotherapy. Eur J Surg Oncol 2011;37:364-9.

15. Mossa B, Mossa S, Corosu L, et al. Follow-up in a long-term randomized trial with neoadjuvant chemotherapy for squamous cell 
cervical carcinoma. Eur J Gynaecol Oncol 2010;31:497-503.

16. Shoji T, Takatori E, Hatayama S, et al. Phase II study of tri-weekly cisplatin and irinotecan as neoadjuvant chemotherapyfor locally advanced cervical cancer. Oncol Lett 2010;1:515-9.

17. Kumar JV, Doval DC, Rao R, et al. A retrospective study of patients with locally advanced cancer of the cervix treated with neoadjuvant chemotherapyfollowed by radical surgery. Int $\mathrm{J}$ Gynecol Cancer 2009;19:417-22.

18. Cho Y, Kim D, Kim J, et al. Comparative study of neoadjuvant chemotherapy before radical hysterectomy and radical surgery alone in stage IB2-IIA bulky cervical cancer. J Gynecol Oncol 2009;20:22-7.

19. Kokawa K, Nishimura R, Fujii T, et al. Neoadjuvant chemotherapy with irinotecan and mitomycin-C for locally advanced squamous cell carcinoma of the uterine cervix. Anticancer Res 2007;27:2721-7.

20. Sláma J, Cibula D, Freitag P, et al. Contribution of neoadjuvant chemotherapy for operability of cancers of the uterine cervix. Ceska Gynekol 2007;72:116-9.

21. Eddy G, Bundy B, Creasman W, et al. Treatment of ("bulky") stage IB cervical cancer with or without neoadjuvant vincristine and cisplatin prior to radical hysterectomy and pelvic/para-aortic lymphadenectomy: a phase III trial of the gynecologic oncology group. Gynecol Oncol 2007;106:362-9.

22. Choi YS, Sin J, Kim J, et al. Survival benefits of neoadjuvant chemotherapy followed by radical surgery versus radiotherapy in locally advanced chemoresistant cervical cancer. J Korean Med Sci 2006;21:683-9.

23. Cai HB, Chen HZ, Yin HH. Randomized study of preoperative chemotherapy versus primary surgery for stage IB cervical cancer. J Obstet Gynaecol Res 2006;32:315-23.

24. Termrungruanglert W, Tresukosol D, Vasuratna A, et al. Neoadjuvant gemcitabine and cisplatin followed by radical surgery in (bulky) squamous cell carcinoma of cervix stage IB2. Gynecol Oncol 2005;97:576-81.

25. Taneja A, Rajaram S, Agarwal S, et al. 'Quick Cycle' neoadjuvant chemotherapy in squamous cell carcinoma of cervix. Indian $\mathrm{J}$ Pharmacol 2005;37:320-4.

26. DeSouza NM, Soutter WP, Rustin G, et al. Use of neoadjuvant chemotherapy prior to radical hysterectomy in cervical cancer: monitoring tumour shrinkage and molecular profile on magnetic resonance and assessment of 3 -year outcome. Br J Cancer 2004;90:2326-31.

27. Hwang YY, Moon H, Cho SH, et al. Ten-year survival of patients with locally advanced, stage ib-iib cervical cancer after neoadjuvant chemotherapy and radical hysterectomy. Gynecol Oncol 2001;82:88-93.

28. Napolitano U, Imperato F, Mossa B, et al. The role of neoadjuvant chemotherapy for squamous cell cervical cancer (Ib-IIIb): a longterm randomized trial. Eur J Gynaecol Oncol 2003;24:51-9.

29. D’Agostino G, Distefano M, Greggi S, et al. Neoadjuvant treatment of locally advanced carcinoma of the uterine cervix with epirubicin, paclitaxel and cisplatin. Cancer Chemother Pharmacol 2002; 49:256-60.

30. Benedetti-Panici P, Greggi S, Colombo A, et al. Neoadjuvant chemotherapy and radical surgery versus exclusive radiotherapy in locally advanced squamous cell cervical cancer: results from the Italian Multicenter Randomized Study. J Clin Oncol 2002;20:179-88.

31. Dueñas-Gonzalez A, López-Graniel C, González-Enciso A, et al. A phase II study of multimodality treatment for locally advanced cervical cancer: neoadjuvant carboplatin and paclitaxel followed by radical hysterectomy and adjuvant cisplatin chemoradiation. Ann Oncol 2003;14:1278-84.

32. Duenas-Gonzalez A, Lopez-Graniel C, Gonzalez-Enciso A, et al. Concomitant chemoradiation versus neoadjuvant chemotherapy in locally advanced cervical carcinoma: results from two consecutive phase II studies. Ann Oncol 2002;13:1212-19.

33. Costa S, Terzano P, Santini D, et al. Neoadjuvant chemotherapy in cervical carcinoma. Regulators of cell cycle, apoptosis, and proliferation as determinants of response to therapy and disease outcome. Am J Clin Pathol 2001;116:729-37.

34. MacLeod C, O'Donnell A, Tattersall MH, et al. Locally advanced cervix cancer: chemotherapy prior to definitive surgery or radiotherapy. A single institutional experience. Australas Radiol 2001;45:491-5.

35. Aoki Y, Tomita M, Sato T, et al. Neoadjuvant chemotherapy for patients younger than 50 years with high-risk squamous cell carcinoma of the cervix. Gynecol Oncol 2001;83:263-7.

36. Hwang Y, Moon H, Cho S, et al. Ten-year survival of patients with locally advanced, stage ib-iib cervical cancer after neoadjuvant chemotherapy and radical hysterectomy. Gynecol Oncol 2001;82:88-93.

37. Chang TC, Lai CH, Hong JH, et al. Randomized trial of neoadjuvant cisplatin, vincristine, bleomycin, and radical hysterectomy versus radiation therapy for bulky stage IB and IIA cervical cancer. J Clin Oncol 2000;18:1740-7.

38. Zanetta G, Lissoni A, Pellegrino A, et al. Neoadjuvant chemotherapy with cisplatin, ifosfamide and paclitaxel for locally advanced squamous-cell cervical cancer. Ann Oncol 1998;9:977-80.

39. Sardi J, Giaroli A, Sananes C, et al. Long-term follow-up of the first randomized trial using neoadjuvant chemotherapyin stage Ib squamous carcinoma of the cervix: the final results. Gynecol Oncol 1997;67:61-9.

40. Lacava JA, Leone BA, Machiavelli M, et al. Vinorelbine as neoadjuvant chemotherapy in advanced cervical carcinoma. J Clin Oncol 1997;15:604-9.

41. Moher D, Liberati A, Tetzlaff J, et al. Preferred reporting items for systematic reviews and meta-analyses: the PRISMA statement. BMJ 2009;339:b2535.

42. Garg A, Hackam D, Tonelli M. Systematic review and meta-analysis: when one study is just not enough. Clin J Am Soc Nephrol 2008;3: 253-60.

43. Morris M, Eifel PJ, Lu J, et al. Pelvic radiation with concurrent chemotherapy versus pelvic and para-aortic radiation for high-risk cervical cancer: a randomized Radiation Therapy Oncology Group clinical trial. N Engl J Med 1999;340:1137-43.

44. Lorusso D, Petrelli F, Coinu A, et al. A systematic review comparing cisplatin and carboplatin plus paclitaxel-based chemotherapy for recurrent or metastatic cervical cancer. Gynecol Oncol 2014; 133:117-23. 